\title{
Predictors of pulmonary tuberculosis treatment outcomes in South Korea: a prospective cohort study, 2005-2012
}

Hongjo Choi ${ }^{1,2}$, Myungsun Lee ${ }^{1}$, Ray Y Chen ${ }^{3}$, Youngran Kim', Soyoung Yoon ${ }^{1}$, Joon Sung Joh ${ }^{4}$, Seung Kyu Park ${ }^{5}$, Lori E Dodd ${ }^{6}$, Jongseok Lee ${ }^{1}$, Taeksun Song ${ }^{1}$, Ying Cai ${ }^{3}$, Lisa C Goldfeder ${ }^{3}$, Laura E Via ${ }^{3}$, Matthew W Carroll3, Clifton E Barry $3 \mathrm{rd}^{3}$ and Sang-Nae Cho ${ }^{1,7^{*}}$

\begin{abstract}
Background: Tuberculosis remains an important health concern in many countries. The aim of this study was to identify predictors of unfavorable outcomes at the end of treatment (EOT) and at the end of study (EOS; 40 months after EOT) in South Korea.

Methods: New or previously treated tuberculosis patients were recruited into a prospective observational cohort study at two hospitals in South Korea. To identify predictors of unfavorable outcomes at EOT and EOS, logistic regression analysis was performed.
\end{abstract}

Results: The proportion of multidrug-resistant tuberculosis (MDR-TB) was $8.2 \%$ in new cases and $57.9 \%$ in previously treated cases. Of new cases, $68.6 \%$ were cured, as were $40.7 \%$ of previously treated cases. At EOT, diabetes, $\geq 3$ previous TB episodes, $\geq 1$ significant regimen change, and MDR-TB were significantly associated with treatment failure or death. At EOS, age $\geq 35$, body-mass index (BMI) $<18.5$, diabetes, and MDR-TB were significantly associated with treatment failure, death, or relapse. Among cases that were cured at EOT, age $\geq 50$ and a $\mathrm{BMI}<18.5$ were associated with subsequent death or relapse during follow-up to EOS. Treatment interruption was associated with service sector employees or laborers, bilateral lesions on chest X-ray, and previous treatment failure or treatment interruption history.

Conclusions: Risk factors for poor treatment outcomes at EOT and EOS include both patient factors (diabetes status, age, BMI) and disease factors (history of multiple previous treatment episodes, MDR-TB). In this longitudinal, observational cohort study, diabetes mellitus and MDR-TB were risk factors for poor treatment outcomes and relapse. Measures to help ensure that the first tuberculosis treatment episode is also the last one may improve treatment outcomes.

Trial registration: ClinicalTrials.gov ID: NCT00341601 registered on June 19, 2006

Keywords: Multidrug-resistant tuberculosis, Tuberculosis, Diabetes, Unfavorable outcome, Long-term follow up, South Korea

\section{Background}

Tuberculosis (TB), a global concern for both developing and developed countries, has recently become more complex due to increasing levels of drug resistance and HIV co-infection [1]. Asian and African countries share the highest burden of tuberculosis, accounting for about

\footnotetext{
* Correspondence: raycho@yonsei.kr

${ }^{1}$ International Tuberculosis Research Center, Changwon, Republic of Korea

${ }^{7}$ Department of Microbiology and Institute for Immunology and

Immunological Diseases, Brain Korea 21 Project for Medical Science, Yonsei

University College of Medicine, Seoul, Republic of Korea

Full list of author information is available at the end of the article
}

$85 \%$ of the 8.6 million newly diagnosed TB cases reported globally in 2012 [2]. Efforts to reduce disease burden have been largely focused on improving treatment and diagnosis of patients with active disease [3]. Although HIV co-infection and multidrug-resistant (MDR) TB are major contributors to the global TB epidemic [4], a deeper understanding of other risk factors for poor outcome can suggest interventions that might help reduce morbidity and mortality. Poor socioeconomic status, including poverty, lack of education, and urbanization are known risk factors for active tuberculosis 
Table 1 Comparisons of baseline characteristics by new or previously treated cases $(n=669)$

\begin{tabular}{|c|c|c|c|c|}
\hline \multirow[t]{2}{*}{ Variables } & & \multicolumn{2}{|r|}{ Group (\%) } & \multirow{2}{*}{$\begin{array}{c}P \text { - } \\
\text { value }\end{array}$} \\
\hline & & New case & Previously treated case & \\
\hline \multicolumn{5}{|l|}{ Demographic } \\
\hline \multirow[t]{2}{*}{ Gender } & Female & $36(16.1)$ & $70(15.7)$ & 0.909 \\
\hline & Male & $188(83.9)$ & $375(84.3)$ & \\
\hline \multirow[t]{3}{*}{ Age } & $20-34$ & $47(21.0)$ & $122(27.4)$ & 0.158 \\
\hline & $35-49$ & $95(42.4)$ & $183(41.1)$ & \\
\hline & $50-$ & $82(36.6)$ & $140(31.5)$ & \\
\hline \multicolumn{5}{|l|}{ Health condition } \\
\hline \multirow[t]{2}{*}{ BMI $(n=626)$} & $<18.5$ & $108(50.2)$ & $204(49.6)$ & 0.887 \\
\hline & $18.5-$ & $107(49.8)$ & $207(50.4)$ & \\
\hline \multirow[t]{2}{*}{ Diabetes } & No & $180(80.4)$ & $340(76.4)$ & 0.246 \\
\hline & Yes & 44 (19.6) & 105 (23.6) & \\
\hline \multicolumn{5}{|l|}{ Individual behavior } \\
\hline \multirow[t]{3}{*}{ Alcohol, within 6 months } & Less than once a week & $102(45.5)$ & $245(55.1)$ & 0.062 \\
\hline & Several times a week & $39(17.4)$ & $68(15.3)$ & \\
\hline & At least once a day & $83(37.1)$ & $132(29.7)$ & \\
\hline \multirow[t]{4}{*}{ Smoking, within 6 months } & Never smoked & $56(25.0)$ & $125(28.1)$ & $<0.001$ \\
\hline & $<1$ pack/day & $30(12.39)$ & $125(28.1)$ & \\
\hline & 1 pack/day & $78(34.8)$ & $121(27.2)$ & \\
\hline & $>1$ pack/day & $60(26.8)$ & $74(16.6)$ & \\
\hline \multicolumn{5}{|l|}{ Socioeconomic } \\
\hline \multirow[t]{2}{*}{ Residential area } & Small city and town & $135(60.3)$ & $245(55.1)$ & 0.199 \\
\hline & Large city & $89(39.7)$ & $200(44.9)$ & \\
\hline \multirow[t]{2}{*}{ Education } & High school, above & $120(53.6)$ & $251(56.4)$ & 0.487 \\
\hline & Middle school, below and refusal & $104(46.4)$ & $194(43.6)$ & \\
\hline \multirow[t]{3}{*}{ Occupation } & Health care, professional, office work & $16(7.1)$ & $55(12.4)$ & 0.117 \\
\hline & $\begin{array}{l}\text { Service sector and laborer in construction } \\
\text { or factory }\end{array}$ & $128(57.1)$ & $242(54.4)$ & \\
\hline & Unemployment and others & $80(35.7)$ & $148(33.3)$ & \\
\hline \multirow[t]{2}{*}{ Housing status $(n=668$ ) } & Private & $201(89.7)$ & $415(93.5)$ & 0.089 \\
\hline & Other & $23(10.3)$ & $29(6.5)$ & \\
\hline \multicolumn{5}{|l|}{ Tuberculosis-related clinical } \\
\hline \multicolumn{5}{|l|}{ Chest $X$ ray } \\
\hline \multirow[t]{3}{*}{ Grade } & Minimal & $10(4.5)$ & $9(2.0)$ & 0.020 \\
\hline & Moderately advanced & $111(49.6)$ & $187(42.0)$ & \\
\hline & Far advanced & $103(46.0)$ & $249(56.0)$ & \\
\hline \multirow[t]{3}{*}{ Cavity } & Yes & $138(61.6)$ & $281(63.1)$ & $<0.001$ \\
\hline & No & $68(30.4)$ & $78(17.5)$ & \\
\hline & Not clear & $18(8.0)$ & $86(19.3)$ & \\
\hline \multirow[t]{2}{*}{ Bilateral } & Unilateral & $57(25.4)$ & $56(12.6)$ & $<0.001$ \\
\hline & Bilateral & $167(74.6)$ & $389(87.4)$ & \\
\hline \multirow[t]{2}{*}{ Nodular lesion } & Yes & $199(88.8)$ & $417(93.7)$ & $0.038^{*}$ \\
\hline & No & $22(9.8)$ & $27(6.1)$ & \\
\hline
\end{tabular}


Table 1 Comparisons of baseline characteristics by new or previously treated cases $(\mathrm{n}=669)$ (Continued)

\begin{tabular}{|c|c|c|c|c|}
\hline & Not clear & $3(1.3)$ & $1(0.2)$ & \\
\hline \multicolumn{5}{|l|}{ Treatment History } \\
\hline \multirow[t]{4}{*}{ Number of previous treatment episode $(n=444)$} & 1 & - & $151(33.9)$ & - \\
\hline & 2 & - & $106(23.8)$ & \\
\hline & 3 & - & $63(14.2)$ & \\
\hline & 4 or more & - & $125(28.1)$ & \\
\hline Cumulative duration of previous treatment (days, $n=444$ ) & Median (IQR) & - & $304(61-761)$ & - \\
\hline \multirow[t]{2}{*}{ History of failure $(n=445)$} & No & - & $249(56.0)$ & - \\
\hline & Yes & - & $196(44.0)$ & \\
\hline \multirow[t]{2}{*}{ History of treatment interruption $(n=445)$} & No & - & $207(46.5)$ & - \\
\hline & Yes & - & $238(53.5)$ & \\
\hline \multirow[t]{4}{*}{ Drug Susceptibility pattern $(n=581)$} & DS & $146(75.0)$ & $92(26.5)$ & $<0.001^{*}$ \\
\hline & Mono/Poly-R & $29(14.8)$ & $44(11.4)$ & \\
\hline & Rif, mono-R & $4(2.0)$ & $16(4.2)$ & \\
\hline & MDR & $16(8.2)$ & $223(57.9)$ & \\
\hline \multicolumn{5}{|l|}{ AFB smear score at baseline } \\
\hline & - & $1(0.5)$ & $4(0.9)$ & $0.689^{*}$ \\
\hline & Scant & $51(22.8)$ & $85(19.1)$ & \\
\hline & $1+$ & $121(54.0)$ & $247(55.5)$ & \\
\hline & $\geq 2+$ & $51(22.8)$ & $109(24.5)$ & \\
\hline
\end{tabular}

*Tested by Fisher's exact test.

BMI: Body mass index; DS: Drug susceptible, Mono/poly-R: mono or poly-drug resistance that is not matched with the definition of Multidrug-resistant tuberculosis; MDR: multidrug-resistant tuberculosis.

[5,6]. Smoking and other behaviors such as alcohol consumption and drug use are also associated with poor treatment outcomes [7-10]. Clinical characteristics including diabetes, baseline disease severity (on chest X-ray), previous treatment history, and drugresistance have all been shown to be independent risk factors for poor treatment outcomes in previous studies [11-13].

Few studies have prospectively identified factors associated with long-term prognosis. A retrospective study by Kim et al [14] evaluated long-term prognostic factors among MDR-TB patients and found that having extensively drug resistant (XDR) TB was the strongest predictor of poor outcomes. Two other studies evaluated the characteristics of patients with tuberculosis relapse after treatment completion [15,16]. In one, a prior history of TB treatment was the largest risk factor associated with TB recurrence (HR: 5.2, CI: 1.7-16.2) [16] and, in another, DNA fingerprinting of cases of recurrent TB suggested that those previously infected with TB are at increased risk of developing TB again when re-infected [15]. This study aims to identify predictors with unfavorable outcome at the end of therapy and the long-term unfavorable outcome after treatment completion in South Korea.

\section{Methods}

Study population and design

Subjects in this study were recruited prospectively into an observational cohort study at the National Masan Tuberculosis Hospital and the National Medical Center in South Korea (ClinicalTrials.gov ID: NCT00341601). Both new and previously treated tuberculosis cases [defined according to World Health Organization (WHO) definitions] [17] were enrolled in this study. The inclusion criteria allowed enrollment of adults 20 years or older who had clinical signs or symptoms suggestive of $\mathrm{TB}$, and had either a positive sputum smear for acid-fast bacilli or confirmed Mycobacterium tuberculosis in their sputum using any molecular method. In addition, new cases could not have had a treatment interruption lasting more than 60 days and must have had at least 4 months of treatment remaining in their current episode of TB. Previously treated cases must either have previously been treated for more than 30 days followed by a treatment interruption of at least 60 days or have had a history of treatment failure or chronic tuberculosis.

According to Korean tuberculosis guidelines [18], drugresistant TB patients are treated with an individualized regimen based on results of drug-susceptibility testing. For drug-susceptible and new patients, hospital guidelines 
recommend a 9-month treatment duration except for cases with minimal disease that are initially sputum smear and culture negative. In this study, regular follow-up was conducted by medical chart abstraction or phone call at 3 to 6 month intervals; the final follow-up was performed up to 40 months after treatment completion. Data collected from 2005-2012 are included in this study.

\section{Measurements and definitions}

Treatment outcomes were categorized as cure, failure, treatment interruption, unknown, death, relapse or withdrawal and were assessed at both the end of treatment (EOT) and the end of study (EOS) follow-up phone call. Treatment outcomes at EOT were defined as follows: a) cure was defined as a patient who was initially sputum smear-positive and who was sputum smear-negative in the last month of treatment and on at least one previous occasion, per the WHO Global Tuberculosis Report 2013 [2]; b) failure was defined as 6-month sputum culture positivity for drug-susceptible (DS) cases and treatment termination or need for permanent regimen change of at least two anti-TB drugs for rifampin-resistant (RR) and
MDR cases; c) treatment interruption (TI) was defined as voluntary cessation of therapy for 2 or more consecutive months without restarting the same regimen within 6 months; d) death was defined as a case who died for any reason during the treatment course; e) unknown was defined as a case whose treatment outcome was not known, including loss to follow-up and lack of microbiologic information at EOT; f) withdrawal was defined as a case who withdrew from the study before treatment completion. Treatment outcomes at EOS were assessed approximately 40 months after treatment completion as follows: i) cure was defined as a case who was cured at EOT and completed the study without relapse, death, or withdrawal; ii) failure was defined as culture positivity 2 years after treatment initiation, regardless of drug-resistance; iii) death was defined as a case who died for any reason during the entire study period; iv) relapse was defined as a case who reinitiated $\mathrm{TB}$ treatment after being designated a cure at treatment completion.

Demographic information, including gender, age, residential area (e.g. large or small city), and socioeconomic factors, including education, occupation and housing

Table 2 Comparisons of treatment-course related characteristics of study population at the end of therapy by new or previously treated status $(n=669)$

\begin{tabular}{|c|c|c|c|}
\hline Variables (n) & New case & Previously treated case & $P$-value \\
\hline \multicolumn{4}{|l|}{ Number of significant regimen change } \\
\hline 0 & $194(86.6)$ & $311(69.9)$ & \multirow[t]{2}{*}{$<0.001$} \\
\hline$\geq 1$ & $30(13.4)$ & $134(30.1)$ & \\
\hline \multicolumn{4}{|l|}{ Elevation of total bilirubin } \\
\hline No & $143(63.8)$ & $307(69.0)$ & \multirow[t]{2}{*}{0.180} \\
\hline Yes & $81(36.2)$ & $138(31.0)$ & \\
\hline \multicolumn{4}{|l|}{ Elevation of liver enzyme } \\
\hline No & $181(80.8)$ & $365(82.0)$ & \multirow[t]{2}{*}{0.701} \\
\hline Yes & $43(19.2)$ & $80(18.0)$ & \\
\hline Months to treatment completion, median (IQR) & $9.45(8.89-12.23)$ & $14.97(9.67-26.10)$ & $<0.001+$ \\
\hline \multicolumn{4}{|l|}{ Treatment outcome at EOT } \\
\hline Cured & $154(68.8)$ & $181(40.7)$ & \multirow[t]{6}{*}{$<0.001^{*}$} \\
\hline Failure & $4(1.8)$ & $61(13.7)$ & \\
\hline $\mathrm{Tl}$ & $35(15.6)$ & $87(19.6)$ & \\
\hline Unknown & $15(6.7)$ & $50(11.2)$ & \\
\hline Death & $6(2.7)$ & $44(9.9)$ & \\
\hline Withdrawal & $10(4.5)$ & $22(4.9)$ & \\
\hline \multicolumn{4}{|l|}{ Culture positivity (since enrollment) } \\
\hline Converted prior to 6 months & $145(64.7)$ & $245(55.1)$ & \multirow[t]{3}{*}{0.001} \\
\hline Positivity at 6 months, over & $14(6.2)$ & $71(16.0)$ & \\
\hline Unknown 6 month result & $65(29.0)$ & $129(29.0)$ & \\
\hline Months to $\mathrm{TI}$, median (IQR) & $7.98(5.02-10.32)$ & $9.67(6.60-17.83)$ & $0.013 \dagger$ \\
\hline
\end{tabular}

*Tested by Fisher's exact test.

† Tested by Mann-Whitney test.

AFB: Acid fast bacilli; IQR: Interquartile range; EOT: End of therapy; TI: Treatment interruption. 
Table 3 Predictors of unfavorable outcome (compared to cure) assessed at the end of therapy $(n=403)+$

\begin{tabular}{|c|c|c|c|c|c|}
\hline \multirow[t]{2}{*}{ Variable } & & \multicolumn{2}{|c|}{ Univariate } & \multicolumn{2}{|c|}{ Multivariate‡ } \\
\hline & & OR & $95 \% \mathrm{Cl}$ & OR & $95 \% \mathrm{Cl}$ \\
\hline \multirow[t]{2}{*}{ Gender } & Female & 1 & & 1 & \\
\hline & Male & 1.04 & $0.57-1.87$ & 0.92 & $0.42-2.01$ \\
\hline \multirow[t]{3}{*}{ Age } & $20-34$ & 1 & & 1 & \\
\hline & $35-49$ & 1.09 & $0.64-1.85$ & 1.00 & $0.48-2.09$ \\
\hline & $\geq 50$ & 0.70 & $0.39-1.24$ & 0.78 & $0.35-1.72$ \\
\hline \multirow[t]{2}{*}{ Body Mass Index } & $<18.5$ & 1 & & - & \\
\hline & $\geq 18.5$ & 0.86 & $0.55-1.34$ & & \\
\hline \multirow[t]{2}{*}{ Diabetes } & No & 1 & & 1 & \\
\hline & Yes & $1.78^{*}$ & $1.07-2.95$ & $2.52^{* *}$ & $1.27-5.01$ \\
\hline \multirow[t]{3}{*}{ Alcohol, within 6 months } & Less than once a week & 1 & & 1 & \\
\hline & Several times a week & $0.40^{*}$ & $0.19-0.83$ & $0.38^{*}$ & $0.16-0.93$ \\
\hline & At least once a day & $0.59^{* *}$ & $0.36-0.98$ & 1.10 & $0.56-2.19$ \\
\hline \multirow[t]{4}{*}{ Smoking, within 6 months } & Never smoked & 1 & & - & \\
\hline & $<1$ pack/day & 1.11 & $0.63-1.94$ & & \\
\hline & 1 pack/day & $0.39^{* *}$ & $0.21-0.72$ & & \\
\hline & $>1$ pack/day & 0.58 & $0.30-1.13$ & & \\
\hline \multirow[t]{2}{*}{ Residential area } & Small city and town & 1 & & - & \\
\hline & Large city & $1.70^{*}$ & $1.10-2.64$ & & \\
\hline \multirow[t]{2}{*}{ Education } & High school, above & 1 & & - & \\
\hline & Middle school, below or refusal & 0.73 & $0.47-1.15$ & & \\
\hline \multirow[t]{3}{*}{ Occupation } & Health care, professional and office work & 1 & & - & \\
\hline & Service sector and laborer & $0.44^{*}$ & $0.23-0.83$ & & \\
\hline & Unemployment and others & 0.56 & $0.29-1.08$ & & \\
\hline \multicolumn{6}{|l|}{ Chest X-ray } \\
\hline \multirow[t]{2}{*}{ Grade } & Minimal or moderate & 1 & & - & \\
\hline & Far advanced & $1.63^{*}$ & $1.05-3.54$ & & \\
\hline \multirow[t]{2}{*}{ Cavity } & No & 1 & & - & \\
\hline & Yes or not clear & $1.88^{*}$ & $1.02-3.45$ & & \\
\hline \multirow[t]{2}{*}{ Nodular lesion } & No & 1 & & - & \\
\hline & Yes or not clear & 1.48 & $0.59-3.76$ & & \\
\hline \multirow[t]{2}{*}{ Bilateral } & Unilateral & 1 & & - & \\
\hline & Bilateral & $3.45^{* *}$ & $1.66-7.19$ & & \\
\hline \multirow[t]{5}{*}{ Number of previous treatment episodes } & 0 (new case) & 1 & & 1 & \\
\hline & 1 & $2.50^{*}$ & $1.05-5.96$ & 2.38 & $0.91-6.25$ \\
\hline & 2 & $5.02^{* * *}$ & $2.11-11.93$ & 2.03 & $0.72-5.79$ \\
\hline & 3 & $10.27^{* * *}$ & $4.05-26.04$ & $3.28^{*}$ & $1.06-10.14$ \\
\hline & $\geq 4$ & $28.54^{* * *}$ & $13.30-61.24$ & $10.30^{* * *}$ & $3.79-27.94$ \\
\hline \multirow[t]{2}{*}{ History of failure } & No & 1 & & - & \\
\hline & Yes & $8.00^{* * *}$ & $4.93-12.99$ & & \\
\hline \multirow[t]{2}{*}{ History of TI } & No & 1 & & - & \\
\hline & Yes & $2.15^{* *}$ & $1.37-3.38$ & & \\
\hline \multirow[t]{2}{*}{ Number of significant regimen changes } & 0 & 1 & & 1 & \\
\hline & $\geq 1$ & $7.26^{* * *}$ & $4.53-11.64$ & $4.01^{* * *}$ & $2.16-7.44$ \\
\hline
\end{tabular}


Table 3 Predictors of unfavorable outcome (compared to cure) assessed at the end of therapy $(n=403)+($ Continued)

\begin{tabular}{llcccc}
\hline Drug susceptibility pattern & DS & 1 & & 1 & \\
& Mono/poly-R & 2.40 & $0.93-6.18$ & 0.93 & $0.31-2.78$ \\
& Rif, mono-R & 2.74 & $0.53-14.00$ & 0.58 & $0.07-4.46$ \\
& MDR & $14.18^{* * *}$ & $7.47-26.90$ & $2.75^{*}$ & $1.13-6.72$ \\
\hline
\end{tabular}

${ }^{*} \mathrm{p}<0.05,{ }^{* *} \mathrm{p}<0.01,{ }^{* * *} \mathrm{p}<0.001$.

† Favorable outcome is cured $(n=289)$ and unfavorable outcome includes failure $(n=65)$ and death $(n=49)$ assessed at the end of therapy.

‡ Multivariate model includes age, gender and all significant factors from the univariate model.

TI: treatment interruption; DS: Drug susceptible, Mono/poly-R: mono or poly-drug resistance that is not matched with the definition of multidrug-resistant tuberculosis

or rifampin mono resistance; MDR: multidrug-resistant tuberculosis.

status, were collected upon study entry. Age was categorized into three groups $(20-34,35-49$, and $\geq 50)$ for the purposes of analysis. Relevant subject medical history that was collected included: alcohol consumption, smoking history, diabetes mellitus status, and previous tuberculosis treatment history, including drug-susceptibility testing (DST), elevation of total bilirubin, elevation of liver enzymes (alanine aminotransferase and aspartate aminotransferase) and chest X-ray reports. Korean tuberculosis guidelines define 'far advanced' disease on chest X-ray as "disseminated lesions of slight to moderate density exceeding the total volume of one lung or dense and confluent lesions exceeding one third the volume of one lung or the presence of cavities greater than $4 \mathrm{~cm}$ in diameter" [18]. A significant regimen change was defined as: i) any change from $1^{\text {st }}$-line drugs to $2^{\text {nd }}$-line drugs; ii) adding either a later generation fluoroquinolone or linezolid to baseline $2^{\text {nd }}$-line drugs; or iii) adding 2 or more classes of $2^{\text {nd }}$-line drugs.

\section{Statistical methods}

Comparisons of characteristics between patients who were new and previously treated were conducted using the Mann-Whitney test for continuous variables and Fisher's exact test if any value was less than 5 in a cell or Pearson's $X^{2}$ test for categorical variables. The first comparison was performed to identify factors associated with unfavorable outcomes (failure or death) versus cure at EOT using logistic regression. A second comparison was conducted to identify factors associated with unfavorable outcomes (failure, death, or relapse) compared to cure at EOS by binary logistic regression. A third logistic regression was performed looking at risk factors for treatment interruptions (relative to those cured). Finally, Cox proportional hazards regression analysis was used to identify factors associated with unfavorable outcomes (death or relapse) at EOS among those cured at EOT. All multivariate models considered age, gender, and all variables that were univariately significant. With the exception of age and gender, variables that were no longer significant in the multivariate model were dropped. Statistical analyses were performed with Stata/SE 12.0 (Stata Corp., College Station, TX,
USA) with $P$ value $<0.05$ as the criterion for statistical significance.

\section{Ethics}

Informed consent was obtained from all participants in the study. This study was approved by the Institutional Review Boards of the National Medical Center and the National Masan Tuberculosis Hospital in South Korea, and the National Institute of Allergy and Infectious Diseases in the U.S. This study was conducted in accordance with ICH-GCP and monitored by an independent clinical research organization.

\section{Results}

\section{Baseline and treatment characteristics}

A total of 669 patients were enrolled in the study from 2005-2012, 563 (84.2\%) of whom were male with a median age of 44 years. Except for smoking history and tuberculosis-related clinical factors, there were no significant differences in baseline characteristics between new and previously treated cases. Compared with new cases, previously treated patients presented with similar sputum smear scores but significantly more advanced and bilateral disease on baseline chest X-ray and more drug resistance (Table 1).

By EOT, the previously treated group experienced significantly more regimen changes. Previously treated cases had lower proportions of cured and higher proportions of failed, unknown outcomes, and deaths compared to new cases (Table 2).

\section{Predictors of unfavorable outcomes at the end of treatment} Among the 403 patients with complete information available at EOT, 289 (71.7\%) were cured, 65 failed, and 49 died. The multivariate analysis of baseline risk factors associated with unfavorable outcomes (failure or death) at $\mathrm{EOT}$ included diabetes $(\mathrm{OR}=2.52 ; 95 \% \mathrm{CI}=1.27$ 5.01), patients drinking several times a week $(\mathrm{OR}=0.38$ : $95 \% \mathrm{CI}=0.16-0.93$, compared to drinking less than once a week), $\geq 1$ significant regimen changes $(\mathrm{OR}=4.01 ; 95 \%$ $\mathrm{CI}=2.16-7.44)$, MDR-TB $(\mathrm{OR}=2.75 ; 95 \% \mathrm{CI}=1.13-6.72$, compared to drug-sensitive TB), and patients with 3 or $\geq 4$ previous treatment episodes $(\mathrm{OR}=3.28 ; 95 \% \mathrm{CI}=$ 
Table 4 Predictors of unfavorable outcome (compared to cure) assessed at the end of study $(n=392) \dagger$

\begin{tabular}{|c|c|c|c|c|c|}
\hline \multirow[t]{2}{*}{ Variable } & & \multicolumn{2}{|c|}{ Univariate } & \multicolumn{2}{|c|}{ Multivariate $\ddagger$} \\
\hline & & OR & $95 \% \mathrm{Cl}$ & OR & $95 \% \mathrm{Cl}$ \\
\hline \multirow[t]{2}{*}{ Gender } & Female & 1 & & 1 & \\
\hline & Male & 1.29 & $0.70-2.35$ & 1.14 & $0.59-2.20$ \\
\hline \multirow[t]{3}{*}{ Age } & $20-34$ & 1 & & 1 & \\
\hline & $35-49$ & $1.96^{*}$ & $1.07-3.57$ & $2.14^{*}$ & $1.11-4.14$ \\
\hline & $\geq 50$ & $2.75^{* *}$ & $1.50-5.05$ & $2.97^{* *}$ & $1.51-5.86$ \\
\hline \multirow[t]{2}{*}{ Body Mass Index } & $<18.5$ & 1 & & 1 & \\
\hline & $\geq 18.5$ & $0.47^{* *}$ & $0.31-0.73$ & $0.33^{* * *}$ & $0.20-0.54$ \\
\hline \multirow[t]{2}{*}{ Diabetes } & No & 1 & & 1 & \\
\hline & Yes & $2.47^{* * *}$ & $1.51-4.05$ & $2.57^{* *}$ & $1.46-4.52$ \\
\hline \multirow[t]{3}{*}{ Alcohol, within 6 months } & Less than once a week & 1 & & - & \\
\hline & Several times a week & 0.52 & $0.26-1.05$ & & \\
\hline & At least once a day & 0.92 & $0.58-1.48$ & & \\
\hline \multirow[t]{4}{*}{ Smoking, within 6 months } & Never smoked & 1 & & - & \\
\hline & $<1$ pack/day & 1.71 & $0.99-2.97$ & & \\
\hline & 1 pack/day & 1.14 & $0.66-1.97$ & & \\
\hline & $>1$ pack/day & 1.03 & $0.57-1.89$ & & \\
\hline \multirow[t]{2}{*}{ Residence } & Small city and town & 1 & & - & \\
\hline & Large city & 1.19 & $0.78-1.83$ & & \\
\hline \multirow[t]{2}{*}{ Education } & High school, above & 1 & & - & \\
\hline & Middle school, below or refusal & 1.40 & $0.92-2.15$ & & \\
\hline \multirow[t]{3}{*}{ Occupation } & Health care, professional and office work & 1 & & - & \\
\hline & Service sector and laborer & 1.35 & $0.66-2.76$ & & \\
\hline & Unemployment and others & 1.54 & $0.73-3.24$ & & \\
\hline \multicolumn{6}{|l|}{ Chest X-ray } \\
\hline \multirow[t]{2}{*}{ Grade } & Minimal or moderate & 1 & & - & \\
\hline & Far advanced & $2.09^{* *}$ & $1.35-3.24$ & & \\
\hline \multirow[t]{2}{*}{ Cavity } & No & 1 & & - & \\
\hline & Yes or not clear & 1.25 & $0.72-2.15$ & & \\
\hline \multirow[t]{2}{*}{ Nodular lesion } & No & 1 & & - & \\
\hline & Yes or not clear & 1.44 & $0.60-3.48$ & & \\
\hline \multirow[t]{2}{*}{ Bilateral } & Unilateral & 1 & & - & \\
\hline & Bilateral & $2.67^{* *}$ & $1.38-5.18$ & & \\
\hline \multirow[t]{4}{*}{ Number of previous treatment episodes } & 0 (new case) & 1 & & - & \\
\hline & 1 & 1.7 & $0.90-3.22$ & & \\
\hline & 2 & 1.04 & $0.48-2.27$ & & \\
\hline & $\geq 3$ & $4.66^{* * *}$ & $2.69-8.08$ & & \\
\hline \multirow[t]{2}{*}{ History of failure } & No & 1 & & - & \\
\hline & Yes & $3.32^{* * *}$ & $2.11-5.22$ & & \\
\hline \multirow[t]{2}{*}{ History of TI } & No & 1 & & - & \\
\hline & Yes & $2.26^{* * *}$ & $1.45-3.51$ & & \\
\hline \multirow[t]{2}{*}{ Number of significant regimen changes } & 0 & 1 & & - & \\
\hline & $\geq 1$ & 1.21 & $0.75-1.93$ & & \\
\hline Drug Susceptibility pattern $(n=401)$ & DS & 1 & & 1 & \\
\hline
\end{tabular}


Table 4 Predictors of unfavorable outcome (compared to cure) assessed at the end of study $(\mathbf{n}=\mathbf{3 9 2})+($ Continued)

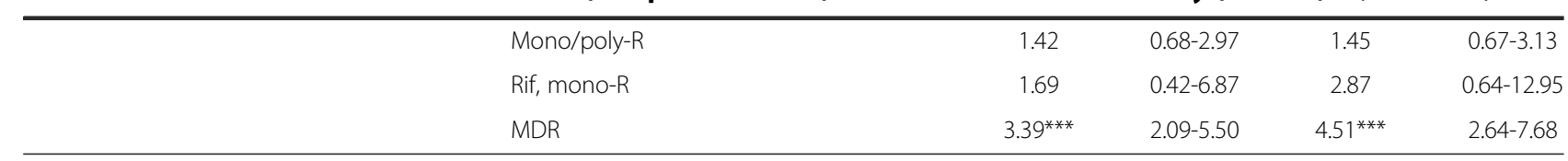

${ }^{*} \mathrm{p}<0.05,{ }^{* *} \mathrm{p}<0.01,{ }^{* * *} \mathrm{p}<0.001$.

† Favorable outcome is cured $(n=267)$ and unfavorable outcome includes failure $(n=22)$, death $(n=86)$ and relapse $(n=17)$ assessed at the end of study. ₹ Multivariate model includes age, gender and all significant factors from the univariate model.

TI: treatment interruption; DS: Drug susceptible, Mono/poly-R: mono or poly-drug resistance that is not matched with the definition of multidrug-resistant tuberculosis or rifampin mono resistance; MDR: multidrug-resistant tuberculosis.

$1.06-10.14$ and $\mathrm{OR}=10.30 ; 95 \% \mathrm{CI}=3.79-27.94$, respectively, compared to no previous treatment episodes) (Table 3). The presence of cavities or bilateral lesions on chest $\mathrm{x}$-ray and having one or more previous treatment failures were significantly associated with unfavorable outcomes in the univariate analysis but not in the multivariate analysis.

\section{Long-term predictors of unfavorable outcomes at the end of study}

Among the 392 patients followed to EOS (40 months after EOT), 267 (67.6\%) were considered cures, 22 failed, 17 relapsed, and 86 died. The multivariate analysis of baseline risk factors associated with unfavorable outcomes (failure, relapse, or death) at EOS included age 35-49 or age $\geq 50 \quad(\mathrm{OR}=2.14 ; 95 \% \mathrm{CI}=1.11-4.14$ and $\mathrm{OR}=2.97$; $95 \% \mathrm{CI}=1.51-5.86$, respectively, compared to those age 20-34), diabetes $(\mathrm{OR}=2.57 ; 95 \% \mathrm{CI}=1.46-4.52)$, and having MDR-TB $(\mathrm{OR}=4.51,95 \% \mathrm{CI}=2.64-7.68$, compared to drug sensitive TB) (Table 4). Having a body-mass index $(\mathrm{BMI}) \geq 18.5$ was associated with cure $(\mathrm{OR}=0.33$; $95 \% \mathrm{CI}=0.20-0.54$, compared to $\mathrm{BMI}<18.5)$. Baseline chest $\mathrm{x}$-ray status and previous treatment history were significantly associated with unfavorable outcomes in the univariate analysis but not in the multivariate analysis.

\section{Predictors of treatment interruption (TI) at the end of therapy}

Among the total 457 patients with full information at EOT, 335 were cured and 122 experienced a TI. In the multivariate analysis compared with those who were cured, those with a TI were significantly more likely to work in the service sector or as a laborer $(\mathrm{OR}=2.30$; $95 \% \mathrm{CI}=1.36-3.90$, compared with those unemployed), present with bilateral lesions on chest $\mathrm{X}$-ray $(\mathrm{OR}=2.46$; $95 \% \mathrm{CI}=1.22-4.95)$, or have a previous treatment failure $(\mathrm{OR}=1.76$; $95 \% \mathrm{CI}=1.04-2.98)$ or previous $\mathrm{TI}(\mathrm{OR}=2.35$; 95\% CI $=1.49-3.70)$ (Table 5).

Long-term prognosis of cured cases at the end of therapy Among the total 289 cured cases with full information at EOT, 278 (96.2\%) cases had full follow-up information to EOS. After treatment completion, there were 20 deaths and 17 relapse cases with full baseline and follow-up information. Age $\geq 50$, BMI and education were associated with death or relapse in univariate analysis. In the multivariate analysis, the factors that remained significant were age $\geq 50 \quad(\mathrm{OR}=3.11 ; 95 \% \mathrm{CI}=1.17-8.26$, compared to those age $20-34)$ and $\mathrm{BMI} \geq 18.5$ being associated with cure $(\mathrm{HR}=0.49 ; 95 \% \mathrm{CI}=0.25-0.95)$. Having MDR-TB at baseline was not a significant prognostic factor in univariate analysis $(\mathrm{HR}=0.87 ; 95 \% \mathrm{CI}=0.40-1.89$; not shown in table) (Table 6).

\section{Discussion}

Multiple previous cohort studies have reported extensively on the risk factors of tuberculosis outcomes, using various measures including relapse $[15,16]$, mortality $[7,10,14,19]$, MDR or XDR-TB status $[11,13,20]$, and treatment failure, TI, or death $[12,21,22]$. In addition, differing study end points were used, including the end of therapy [12,21,22], long term follow up after treatment completion [14-16], and cross-sectional comparison between M/XDR and potential risk factors [11,13,20]. Our study identified factors associated with poor outcomes among all patients at EOT and after long-term follow-up at EOS. In addition, in an effort to separate EOS risk factors from EOT risk factors, an analysis was done to identify factors for relapse or death at EOS just among those considered cured at EOT. At EOT, having diabetes, $\geq 3$ previous treatment episodes, $\geq 1$ significant regimen changes, and MDR-TB were all significantly associated with treatment failure or death (Table 3). At EOS, having diabetes and MDR-TB at baseline continued to be significantly associated with treatment failure, death, or relapse. In addition, baseline age $\geq 35$ and $\mathrm{BMI}<18.5$ were also poor prognostic factors, but the number of previous treatment episodes was no longer significant (Table 4). These risk factors, including age, BMI, and drug resistance pattern, are consistent with those of a previous study with long-term follow-up [14]. These results may suggest that older age and low BMI contribute to relapse or death risk after treatment completion. In isolating risk factors significantly associated with poor outcomes at EOS among cures at EOT, only age $\geq 50$ and baseline BMI $<18.5$ were identified (Table 6 ), suggesting that once a patient is cured, many traditional baseline predictive variables, such as chest $\mathrm{x}$-ray status, previous TB treatment history, and MDR-TB status may no longer 
Table 5 Predictors of treatment interruption (compared to cures) $(n=457) \dagger$

\begin{tabular}{|c|c|c|c|c|c|}
\hline \multirow[t]{2}{*}{ Variable } & & \multicolumn{2}{|c|}{ Univariate } & \multicolumn{2}{|c|}{ Multivariate $\neq$} \\
\hline & & OR & $95 \% \mathrm{Cl}$ & OR & $95 \% \mathrm{Cl}$ \\
\hline \multirow[t]{2}{*}{ Gender } & Female & 1 & & 1 & \\
\hline & Male & 1.48 & $0.79-2.78$ & 1.53 & $0.78-3.00$ \\
\hline \multirow[t]{3}{*}{ Age } & $20-34$ & 1 & & 1 & \\
\hline & $35-49$ & 1.16 & $0.69-1.95$ & 0.92 & $0.53-1.59$ \\
\hline & $\geq 50$ & 0.67 & $0.38-1.18$ & 0.63 & $0.34-1.16$ \\
\hline \multirow[t]{2}{*}{ Body Mass Index $(n=446)$} & $<18.5$ & 1 & & - & \\
\hline & $\geq 18.5$ & 0.78 & $0.51-1.91$ & & \\
\hline \multirow[t]{2}{*}{ Diabetes } & No & 1 & & - & \\
\hline & Yes & 1.56 & $0.95-2.56$ & & \\
\hline \multirow[t]{3}{*}{ Alcohol, within 6 months } & Less than once a week & 1 & & - & \\
\hline & Several times a week & 1.71 & $0.96-3.05$ & & \\
\hline & At least once a day & $2.03^{* *}$ & $1.27-3.24$ & & \\
\hline \multirow[t]{4}{*}{ Smoking, within 6 months } & Never smoked & 1 & & - & \\
\hline & $<1$ pack/day & $2.68^{* *}$ & $1.31-5.49$ & & \\
\hline & 1 pack/day & $3.36^{* * *}$ & $1.75-6.46$ & & \\
\hline & $>1$ pack/day & $3.12^{* *}$ & $1.54-6.32$ & & \\
\hline \multirow[t]{2}{*}{ Residence } & Small city and town & 1 & & - & \\
\hline & Large city & 1.20 & $0.79-1.83$ & & \\
\hline \multirow[t]{2}{*}{ Education } & High school, above & 1 & & - & \\
\hline & Middle school, below or refusal & 1.20 & $0.80-1.82$ & & \\
\hline \multirow[t]{3}{*}{ Occupation } & Unemployment and others & 1 & & 1 & \\
\hline & Health care, professional and office work & 1.14 & $0.47-2.75$ & 0.89 & $0.35-2.25$ \\
\hline & Service sector and laborer & $2.39^{* *}$ & $1.45-3.95$ & $2.30^{* *}$ & $1.36-3.90$ \\
\hline \multicolumn{6}{|l|}{ Chest X-ray } \\
\hline \multirow[t]{2}{*}{ Grade } & Minimal or moderate & 1 & & - & \\
\hline & Far advanced & 1.34 & $0.89-2.04$ & & \\
\hline \multirow[t]{2}{*}{ Cavity } & No & 1 & & - & \\
\hline & Yes or not clear & 1.04 & $0.63-1.69$ & & \\
\hline \multirow[t]{2}{*}{ Nodular lesion } & No & 1 & & - & \\
\hline & Yes or not clear & 2.07 & $0.70-6.14$ & & \\
\hline \multirow[t]{2}{*}{ Bilateral } & Unilateral & 1 & & 1 & \\
\hline & Bilateral & $2.86^{* *}$ & $1.46-5.60$ & $2.46^{*}$ & $1.22-4.95$ \\
\hline \multirow[t]{4}{*}{ Number of previous treatment episode } & 0 (new case) & 1 & & - & \\
\hline & 1 & 1.54 & $0.87-2.71$ & & \\
\hline & 2 & $2.77^{* *}$ & $1.53-5.02$ & & \\
\hline & $\geq 3$ & $2.40^{* *}$ & $1.35-4.27$ & & \\
\hline \multirow[t]{2}{*}{ History of failure } & No & 1 & & 1 & \\
\hline & Yes & $1.81^{*}$ & $1.12-2.92$ & $1.76^{*}$ & $1.04-2.98$ \\
\hline \multirow[t]{2}{*}{ History of TI } & No & 1 & & 1 & \\
\hline & Yes & $2.72^{* * *}$ & $1.77-4.18$ & $2.35^{* * *}$ & $1.49-3.70$ \\
\hline \multirow[t]{2}{*}{ Elevation of total bilirubin } & No & 1 & & & \\
\hline & Yes & $0.63^{*}$ & $0.40-1.00$ & & \\
\hline
\end{tabular}


Table 5 Predictors of treatment interruption (compared to cures) $(n=457)+$ (Continued)

\begin{tabular}{llcc}
\hline Elevation of liver enzyme & No & 1 & \\
Number of significant regimen changes & 0 & 0.95 & $0.55-1.65$ \\
& $\geq 1$ & 1 & \\
Drug susceptibility pattern $(\mathrm{n}=403)$ & $\mathrm{DS}$ & $1.62^{*}$ & $1.04-2.55$ \\
& Mono/poly-R & 1 & \\
& Rif, mono- $\mathrm{R}$ & 1.25 & $0.66-2.39$ \\
& MDR & 2.01 & $0.68-5.92$ \\
\hline
\end{tabular}

${ }^{*} \mathrm{p}<0.05,{ }^{* *} \mathrm{p}<0.01,{ }^{* * *} \mathrm{p}<0.001$.

tTreatment interruption $(n=122)$ was compared with cured $(n=335)$.

¥Multivariate model includes age, gender and all significant factors from the univariate model.

TI: Treatment interruption, DS: Drug susceptible, Mono/poly-R: mono or poly-drug resistance that is not matched with the definition of multidrug-resistant tuberculosis or rifampin mono resistance; MDR: multidrug-resistant tuberculosis.

be as relevant for prognosis. A different study analyzed factors for TB recurrence at EOS after a median 4-year follow-up after EOT and identified inner-city residence, HIV infection, and history of TB treatment as risk factors [16]. This study, however, included all treatmentcompleted patients at EOT regardless of culture conversion status and thus included some patients not fully cured. Future relapse studies among cured patients should be conducted to understand if their risk factors revert back to those similar to the general population.

Some previous studies included TI as an unfavorable outcome (24-26). Because our study population had a relatively high proportion of TI (18.2\%) and reasons for TI may be very different from reasons for failure, death, or relapse, we analyzed this outcome separately, comparing TI cases only to cured cases. Other studies have also

Table 6 Prognostic factors of unfavorable outcome at end of study among cured cases $(n=278) \dagger$

\begin{tabular}{|c|c|c|}
\hline & Adjusted HR & $95 \% \mathrm{Cl}$ \\
\hline \multicolumn{3}{|l|}{ Age } \\
\hline $20-34$ & 1 & \\
\hline $35-49$ & 1.38 & $0.48-3.98$ \\
\hline$\geq 50$ & $3.11^{*}$ & $1.17-8.26$ \\
\hline \multicolumn{3}{|l|}{ Gender } \\
\hline Female & 1 & \\
\hline Male & 1.14 & $0.44-2.95$ \\
\hline \multicolumn{3}{|c|}{ Body Mass Index } \\
\hline$<18.5$ & 1 & \\
\hline$\geq 18.5$ & $0.49^{*}$ & $0.25-0.95$ \\
\hline \multicolumn{3}{|c|}{$\begin{array}{l}\text { *p }<0.05 \text {. } \\
\text { †Among cases who had full information at the end of study, cured cases } \\
(\mathrm{n}=241) \text { were compared with death }(n=20) \text { and relapse }(n=17) \text { cases. } \\
\text { ¥Multivariate model includes age, gender and all significant factors from the } \\
\text { univariate model (omitted in this paper). } \\
\text { TI: Treatment interruption, DS: Drug susceptible, Mono/poly/Rif-R: mono or } \\
\text { poly-drug resistance that is not matched with the definition of } \\
\text { multidrug-resistant tuberculosis; MDR: multidrug-resistant tuberculosis. }\end{array}$} \\
\hline
\end{tabular}

identified risk factors associated specifically with treatment default, including long distance to health facilities, substance use including alcohol consumption, a fear of social stigmatism, unemployment and economic constraint [10,19,23-25]. In our analysis, alcohol consumption and smoking history were associated with TI in the univariate analysis but the significance was lost in the multivariate analysis. Not surprisingly, our study also identified an increased risk for TI among those who previously had a TI or treatment failure. For unclear reasons, having bilateral disease on baseline chest $\mathrm{x}$-ray was associated with TI. Finally, being a blue-collar worker was also risk factor for TI, compared to those who were unemployed. This suggests that perhaps low wage workers had more difficulty getting time off for medical care and may require healthcare policy changes to resolve this issue. Further studies may need to be done to understand better the reasons for TI among service sector employees and laborers. Understanding the causes of TI and how to reduce treatment default is critically important because of the association of TI with the development of drug resistance [26].

Our study has several limitations. First, the study was conducted at two tertiary referral hospitals, which usually manage patients with more severe and extensive disease. This is reflected in our cohort demographics, with most patients having more severe advanced disease on $\mathrm{x}$-ray, including cavities and bilateral disease, as well as the proportion of previously treated cases (compared to new cases) and MDR-TB. Our results, therefore, may not be representative of patients with less severe disease. Second, we only had DST results for 581/669 (86.8\%). Analyses that include DST results exclude patients without DST results, which may cause a selection bias and the point estimates may be over or under-estimated due to the excluded cases. Third, we were not able to measure certain factors possibly related to treatment outcome, including hemoglobin A1c and bacterial load (time to positivity in liquid culture 
system). Fourth, diabetes status collected by self-report and types I vs. II could not be differentiated. Finally, the study was not designed to identify a causal pathway between the independent and outcome variables and was limited to identifying factors associated with unfavorable outcomes and TI.

\section{Conclusions}

This study of risk factors associated with poor treatment outcomes at EOT and EOS highlights both patient specific factors that are difficult to change, such as diabetes status and age, as well as disease specific factors, such as multidrug resistance, that may be affected by programmatic factors and could be altered to improve prognosis. Risk factors related to prolonged disease at diagnosis, including history of multiple previous treatment episodes, emphasize that the initial treatment episode is also likely the best chance of cure. Program management changes should be considered to emphasize public health measures such as directly observed therapy to help ensure that the first treatment episode is also the last one, in conjunction with improving adherence and decreasing the risk of MDR-TB. Policy changes to enable all TB patients, regardless of work status, to have time off to get appropriate treatment would also be important. Finally, steps to improve nutrition and therefore BMI among those successfully treated may help prevent longer-term relapses or recurrences. The treatment of tuberculosis requires a multifaceted approach for the best chance of success.

\section{Competing interests}

The authors declare that they have no competing interests.

\section{Authors' contributions}

HC, ML, TS, YC, LCG, LEV, MWC, SNC, and CEB designed the study. HC, ML, YK. SY, JSJ, and SKP conducted the study and collected the data. JL and TS conducted the laboratory analyses. HC, ML, RYC, and LED analyzed and interpreted the data. $\mathrm{HC}, \mathrm{ML}$, and RYC drafted the manuscript. All authors read and approved the final manuscript.

\section{Acknowledgements}

This study was supported (in part) by the Intramural Research Program of the National Institute of Allergy and Infectious Diseases (NIAID), U.S. National Institutes of Health $(\mathrm{NIH})$, and (in part) by continuous support from the Korean Centers for Disease Control of the Korean Ministry of Health and Welfare to the International Tuberculosis Research Center. Through authors RYC, LED, YC, LCG, LEV, MWC, and CEB, the NIAID, NIH was involved in the design, collection, analysis, and interpretation of data; in writing the manuscript; and in the decision to submit for publication. The Korean Centers for Disease Control was not involved in the design, collection, analysis, and interpretation of data; in writing the manuscript; and in the decision to submit for publication. We would like to thank the patients who enrolled in this research study and the clinical staff who supported the trial.

\section{Author details}

'International Tuberculosis Research Center, Changwon, Republic of Korea. ${ }^{2}$ BK21PLUS Program in Public Health Sciences, Department of Health Sciences, Graduate School, Korea University, Seoul, Republic of Korea. ${ }^{3}$ Tuberculosis Research Section, Laboratory of Clinical Infectious Disease, National Institute of Allergy and Infectious Diseases (NIAID), National Institutes of Health (NIH), Bethesda, Maryland, USA. ${ }^{4}$ Department of Internal Medicine, National Medical Center, Seoul, Republic of Korea. ${ }^{5}$ National Masan
Tuberculosis Hospital, Changwon, Republic of Korea. ${ }^{6}$ Biostatistics Research Branch, NIAID, NIH, Bethesda, Maryland, USA. ${ }^{7}$ Department of Microbiology and Institute for Immunology and Immunological Diseases, Brain Korea 21 Project for Medical Science, Yonsei University College of Medicine, Seoul, Republic of Korea.

Received: 19 February 2014 Accepted: 24 June 2014

Published: 2 July 2014

\section{References}

1. Snider DE, Roper WL: The New tuberculosis. N Engl J Med 1992, 326(10):703-705

2. WHO: Global tuberculosis report 2013. In WHO/HTM/TB/2013.11. Geneva: World Health Organization; 2013.

3. World Health Organization: The global plan to stop TB 2011-2015: transforming the fight towards elimination of tuberculosis. Geneva: World Health Organization; 2010.

4. Gandy M, Zumla A: The resurgence of disease: social and historical perspectives on the 'new'tuberculosis. Soc Sci Med 2002, 55(3):385-396.

5. Lönnroth K, Jaramillo E, Williams BG, Dye C, Raviglione M: Drivers of tuberculosis epidemics: the role of risk factors and social determinants. Soc Sci Med 2009, 68(12):2240-2246.

6. Shetty N, Shemko M, Vaz M, D'Souza G: An epidemiological evaluation of risk factors for tuberculosis in South India: a matched case control study. Int J Tuberc Lung Dis 2006, 10(1):80-86.

7. Reed GW, Choi H, Lee SY, Lee M, Kim Y, Park H, Lee J, Zhan X, Kang H, Hwang S: Impact of Diabetes and Smoking on Mortality in Tuberculosis. PLoS One 2013, 8(2):e58044.

8. Kolappan C, Gopi PG: Tobacco smoking and pulmonary tuberculosis. Thorax 2002, 57(11):964-966.

9. Maciel EL, Brioschi AP, Peres RL, Guidoni LM, Ribeiro FK, Hadad DJ, Vinhas SA, Zandonade E, Palaci M, Dietze R, Johnson JL: Smoking and 2-month culture conversion during anti-tuberculosis treatment. Int I Tuberc Lung Dis 2013, 17(2):225-228.

10. Franke M, Appleton S, Bayona J, Arteaga F, Palacios E, Llaro K, Shin S, Becerra M, Murray M, Mitnick C: Risk factors and mortality associated with default from multidrug-resistant tuberculosis treatment. Clin Infect Dis 2008, 46(12):1844-1851.

11. Faustini A, Hall A, Perucci C: Risk factors for multidrug resistant tuberculosis in Europe: a systematic review. Thorax 2006, 61(2):158.

12. Kim H-R, Hwang SS, Kim HJ, Lee SM, Yoo C-G, Kim YW, Han SK, Shim Y-S, Yim J-J: Impact of extensive drug resistance on treatment outcomes in Non-HIV-infected patients with multidrug-resistant tuberculosis. Clin Infect Dis 2007, 45(10):1290-1295.

13. Dalton T, Cegielski P, Akksilp S, Asencios L, Caoili JC, Cho SN, Erokhin W, Ershova J, Gler MT, Kazennyy BY: Prevalence of and risk factors for resistance to second-line drugs in people with multidrug-resistant tuberculosis in eight countries: a prospective cohort study. Lancet 2012, 380(9851):1406-1417.

14. Kim DH, Kim HJ, Park S-K, Kong S-J, Kim YS, Kim T-H, Kim EK, Lee KM, Lee SS, Park JS Koh WJ, Lee CH, Kim JY, Shim TS: Treatment Outcomes and Long-term Survival in Patients with Extensively Drug-resistant Tuberculosis. Am J Respir Crit Care Med 2008, 178(10):1075-1082.

15. Verver S, Warren RM, Beyers N, Richardson M, van der Spuy GD, Borgdorff MW, Enarson DA, Behr MA, van Helden PD: Rate of reinfection tuberculosis after successful treatment is higher than rate of new tuberculosis. Am J Respir Crit Care Med 2005, 171(12):1430-1435.

16. Millet JP, Shaw E, Orcau A, Casals M, Miro JM, Cayla JA, Barcelona Tuberculosis Recurrence Working G: Tuberculosis recurrence after completion treatment in a European city: reinfection or relapse? PLOS One 2013, 8(6):e64898.

17. World Health Organization: Treatment of tuberculosis guidelines 4th edition. Geneva: World Health Organization; 2010.

18. KCDC: Guideline for tuberculosis control, 2010. Seoul: Korea Centers for Disease Control and Prevention (published in Korean); 2010.

19. Kliiman $\mathrm{K}$, Altraja A: Predictors and mortality associated with treatment default in pulmonary tuberculosis. Int J Tuberc Lung Dis 2010, 14(4):454-463.

20. Jeon C, Hwang S, Min J, Prevots D, Goldfeder L, Lee H, Eum S, Jeon D, Kang $\mathrm{H}$, Kim J: Extensively drug-resistant tuberculosis in South Korea: risk factors and treatment outcomes among patients at a tertiary referral hospital. Clin Infect Dis 2008, 46(1):42-49. 
21. Shin S, Pasechnikov A, Gelmanova I, Peremitin G, Strelis A, Andreev Y, Golubchikova V, Tonkel T, Yanova G, Nikiforov M: Treatment outcomes in an integrated civilian and prison MDR-TB treatment program in Russia. Int J Tuberc Lung Dis 2006, 10(4):402-408.

22. Kwon Y, Kim Y, Suh G, Chung M, Kim H, Kwon OJ, Choi Y, Kim K, Kim J, Shim YM, Koh WJ: Treatment outcomes for HIV-uninfected patients with multidrug-resistant and extensively drug-resistant tuberculosis. Clinical Infectious Diseases 2008, 47(4):496-502.

23. Shargie E, Lindtjorn B: Determinants of treatment adherence among smear-positive pulmonary tuberculosis patients in Southern Ethiopia. PLoS Med 2007, 4(2):e37.

24. Hasker E, Khodjikhanov M, Usarova S, Asamidinov U, Yuldashova U, Werf M Uzakova G, Veen J: Default from tuberculosis treatment in Tashkent, Uzbekistan; Who are these defaulters and why do they default? BMC Infect Dis 2008, 8(1):97.

25. Xu W, Lu W, Zhou Y, Zhu L, Shen H, Wang J: Adherence to anti-tuberculosis treatment among pulmonary tuberculosis patients: a qualitative and quantitative study. BMC Health Serv Res 2009, 9(1):169.

26. Volmink J, Garner P: Systematic review of randomised controlled trials of strategies to promote adherence to tuberculosis treatment. Br Med J 1997, 315(7120):1403-1406.

doi:10.1186/1471-2334-14-360

Cite this article as: Choi et al:: Predictors of pulmonary tuberculosis treatment outcomes in South Korea: a prospective cohort study, 2005-2012. BMC Infectious Diseases 2014 14:360.

\section{Submit your next manuscript to BioMed Central and take full advantage of:}

- Convenient online submission

- Thorough peer review

- No space constraints or color figure charges

- Immediate publication on acceptance

- Inclusion in PubMed, CAS, Scopus and Google Scholar

- Research which is freely available for redistribution 